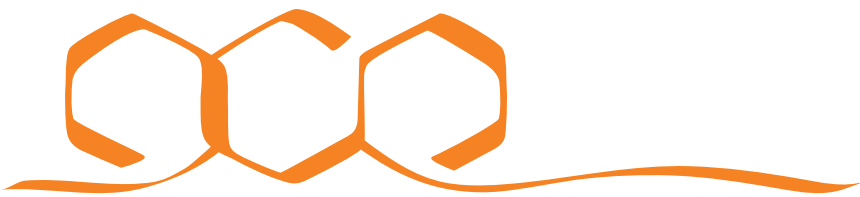 \\ COMMUNICATIONS \\ CHEMISTRY
}

ARTICLE

DOI: $10.1038 / \mathrm{s} 42004-018-0062-7$

OPEN

\section{Accessible and distinct decoquinate derivatives active against Mycobacterium tuberculosis and apicomplexan parasites}

\author{
Richard M. Beteck (10 1, Ronnett Seldon², Dina Coertzen ${ }^{3}$, Mariëtte E. van der Watt ${ }^{3}$, Janette Reader ${ }^{3}$, \\ Jared S. Mackenzie ${ }^{4}$, Dirk A. Lamprecht (10 ${ }^{4}$, Matthew Abraham ${ }^{5}$, Korina Eribez ${ }^{5}$, Joachim Müller ${ }^{6}$, Feng Rui ${ }^{7}$, \\ Guang Zhu7, Ruel Valerio de Grano ${ }^{8}$, lan D. Williams (1) ${ }^{8}$, Frans J. Smit ${ }^{7}$, Adrie J. C. Steyn ${ }^{4}$, \\ Elizabeth A. Winzeler ${ }^{5}$, Andrew Hemphill (1) ${ }^{6}$, Lyn-Marie Birkholtz (1) ${ }^{3}$, Digby F. Warner (10) 9,10, \\ David D. N'Da \& Richard K. Haynes ${ }^{1,8}$
}

The quinolone decoquinate is coadministered with feed for treatment of parasites which cause coccidiosis in poultry. However, from a drug-development perspective, the biological activity is often not adequately exploited due to poor physicochemical properties. Here we convert decoquinate into $\mathrm{N}$-alkyl quinolone amides that, in contrast to decoquinate, are active against the tuberculosis bacterium with $\mathrm{MIC}_{90}$ values ranging from 1.4 to $3.64 \mu \mathrm{M}$, and quinoline $\mathrm{O}$-carbamates active against apicomplexan parasites that cause malaria, toxoplasmosis, and neosporosis with $\mathrm{IC}_{50}$ values of $0.32-1.5 \mathrm{nM}$ for the best derivative. Uniquely for the TB-active amides, disruption of cell wall homoeostasis is identified as one target. With $\mathrm{IC}_{50}$ values against fetal lung fibroblast cells of 40 to $>100 \mu \mathrm{M}$, the derivatives are selective for the pathogens. Structures of the most active derivatives are determined by NMR spectroscopy and X-ray crystallography. Analogues lacking the decyl side chain of decoquinate are inactive.

\footnotetext{
${ }^{1}$ Centre of Excellence for Pharmaceutical Sciences, Faculty of Health Sciences, North-West University, Potchefstroom 2520, South Africa. ${ }^{2}$ H3D Drug Discovery and Development Centre, Department of Chemistry, University of Cape Town, Cape Town 7700, South Africa. ${ }^{3}$ Department of Biochemistry, Genetics and Microbiology, Institute for Sustainable Malaria Control, University of Pretoria, Pretoria 0002, South Africa. ${ }^{4}$ Africa Health Research Institute, Nelson R. Mandela School of Medicine, University of KwaZulu-Natal, Durban 4001, South Africa. ${ }^{5}$ School of Medicine, University of California San Diego, 9500 Gilman Drive 0760, La Jolla, CA 92093, USA. ${ }^{6}$ Institute of Parasitology, Vetsuisse Faculty, University of Berne, Länggass-Strasse 122,3012 Bern, Switzerland. ${ }^{7}$ Division of Life Sciences, The Hong Kong University of Science and Technology, Clear Water Bay, Kowloon, Hong Kong. ${ }^{8}$ Department of Chemistry, The Hong Kong University of Science and Technology, Clear Water Bay, Kowloon, Hong Kong. ${ }^{9}$ SAMRC/NHLS/UCT Molecular Mycobacteriology Research Unit, Department of Pathology and Institute of Infectious Disease and Molecular Medicine, Faculty of Health Sciences, University of Cape Town, Cape Town 7925, South Africa. ${ }^{10}$ Wellcome Centre for Clinical Infectious Diseases Research in Africa, University of Cape Town, Cape Town 7925, South Africa. Correspondence and requests for materials should be addressed to R.M.B. (email: richmbi1@yahoo.com)

or to D.D.N'D. (email: david.nda@nwu.ac.za) or to R.K.H. (email: haynes@ust.hk)
} 
$\mathrm{D}$ eaths from tuberculosis (TB) caused mainly by $\mathrm{Myco-}$ bacterium tuberculosis $(M t b)$ now exceed those of any other infectious disease: in 2016, there were 10.4 million cases and 1.3 million deaths ${ }^{1}$. Inadequate compliance with the current treatment regimens has led to the emergence of resistant $M t b$ strains ranging from multidrug ${ }^{2,3}$ to totally drug-resistant $\mathrm{TB}^{4,5}$. This aspect coupled with toxicities and protracted treatment regiments associated with the use of current TB drugs 6,7 indicate new drugs are urgently needed ${ }^{8,9}$. For malaria, caused mainly by the apicomplexan parasite Plasmodium falciparum $(P f)$, there were 216 million cases and 445,000 deaths in 2016, of which $90 \%$ of cases and $91 \%$ of the deaths occurred in subSaharan Africa ${ }^{10}$. Although mortality has decreased in recent years ${ }^{10}$, the spread of parasites resistant to current drugs including artemisinins is especially problematic in South-East Asia ${ }^{10-12}$. Thus, emphasis is placed on new drug combinations that in addition to acting on asexual blood stage parasites must act on sexually differentiated gametocytes responsible for transmission. One of the most widespread of apicomplexan parasites is Toxoplasma gondii $(\mathrm{Tg})$ that infects both humans and animal species including livestock ${ }^{13} . \mathrm{Tg}$ has a major economic impact, and toxoplasmic encephalitis, especially in immunocompromised patients, and ocular and pulmonary diseases are the most serious clinical manifestations. Current treatments based on combination therapies comprising sulfonamides and pyrimethamine or other antimicrobials are often associated with adverse side effects ${ }^{14}$. Thus, better drugs are required ${ }^{13}$. Neospora caninum $(N c)$ is closely related to $\mathrm{Tg}$, and is a major cause of abortion and stillbirth in cattle. It has a significant veterinary and economic impact, but infection in humans has not been reported to date. No drugs or vaccines are on the market ${ }^{15}$.

Under a programme involving these diseases ${ }^{16}$, we are developing combinations of new artemisinins ${ }^{17}$ with redox or 'prooxidant' drugs ${ }^{18}$ coupled with a third drug. For the last, we focus on quinolones (Fig. 1, structure 1) that are active against all pathogens, but possess distinct mechanisms of action. Quinolones are in clinical use against TB and other infectious diseases ${ }^{19}$, the most prominent of which are fluoroquinolones, e.g. ciprofloxacin (Fig. 1 ${ }^{20}$. The antimalarial activity of quinolones is well established ${ }^{21}$. Newer compounds have enhanced efficacies ${ }^{22-24}$ including ELQ-300 (Fig. 1) ${ }^{25}$ that are also active against transmissible malaria parasites. Quinolones also display activities against $\mathrm{Tg}^{26}$, and here too newer compounds, e.g. ELQ-271 (Fig. 1$)^{27}$ are notably potent.

Thus, the quinolone decoquinate $(\mathrm{DQ}, 2)$ (Fig. 1) is chosen as the incipient template for this work. DQ is used in veterinary practice for treatment of coccidiosis $^{28}$, has a good safety profile ${ }^{29}$ (see also https://www.drugs.com/pro/deccox.html), and is active against both asexual ${ }^{30}$ and sexually differentiated blood stages ${ }^{31}$ of $P f$, and against liver stages of $P$. yoelii $i^{30}$ and $P$. berghei $(P b)^{31}$. DQ is active against $T g^{32}$ where like other quinolones ${ }^{25}$ it exerts activity on the cytochrome $b c$ complex. DQ is economically available, but has the disadvantage of high lipophilicity coupled with exceedingly poor aqueous solubility $(0.06 \mu \mathrm{g} / \mathrm{mL})$. Overall, drug-likeness of DQ should be improved by attaching groups that improve physicochemical properties. However, we are also mindful that for TB, the DQ template is attractive, as the lipophilic decyl side chain should enhance passive diffusion through the mycolic acid cell wall of $M t b$, and of considerable importance for shortening treatment regimen $3^{33,34}$, may assist penetration of infected macrophages and granulomatous lesions encapsulating $M t b$ in various metabolic states, for which indeed, lipophilic molecules appear to be preferred ${ }^{35}$. As far as we are aware, the activity of DQ itself against $M t b$ has not been recorded.

Here we describe the conversion of the ethyl ester unit in DQ into more polar alkoxy esters and less readily metabolized amides $^{16,36-38}$, and attach groups to the quinolone nucleus at $\mathrm{N}-1$ or O-4. In the last case, we focus here on carbamate derivatives: the role of carbamates in enhancing bioavailability of drugs is established $^{39,40}$. Finally, in order to assess the effect of the decyl group on efficacy, we also prepare analogues that lack this lipophilic side chain. The compounds are evaluated in vitro against each of $M t b$, and the apicomplexan parasites $P f, P b, T g$ and $N c$, and cytotoxicities are assessed against a human fetal lung fibroblast cell line.

\section{Results}

Chemical derivatization of decoquinate. The methods used to prepare the DQ derivatives 3-27 are outlined in Fig. 2. Although DQ is relatively acidic ( $\mathrm{p} K_{\mathrm{a}} 9.81$ ), aminolysis with various basic alkyl amines proceeded without incident to provide the amides 3 10 (route i in Fig. 2), as reported previously ${ }^{38}$. For preparation of the $N$-alkyl DQ amides, alkylation of DQ at $\mathrm{N}-1$ is first required. Non activated alkyl halides react via an $\mathrm{S}_{\mathrm{N}} 2$ process with the ambident nucleophile derived from the 4-pyridone system of DQ (Fig. 3), and for such electrophiles, $N$-alkylation predominates ${ }^{41,42}$. In the event DQ was treated with the $1^{\circ}$ alkyl bromide and $\mathrm{K}_{2} \mathrm{CO}_{3}$ in DMF to give the $N$-alkyl intermediates which upon aminolysis provided the $N$-alkyl DQ amides 11-20 (Fig. 2).

For conversion of DQ into derivatives bearing polar groups, reactions with carbamoyl halides were used. For $\mathrm{S}_{\mathrm{N}}$ 1-reactive alkyl halides ${ }^{41,42}$ and acyl halides that react via additionelimination $^{43}$, the 4 -pyridone anion (Fig. 3) predominantly reacts

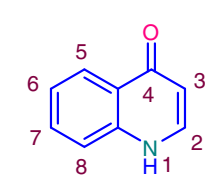

1: $4(1 H)$-Quinolone

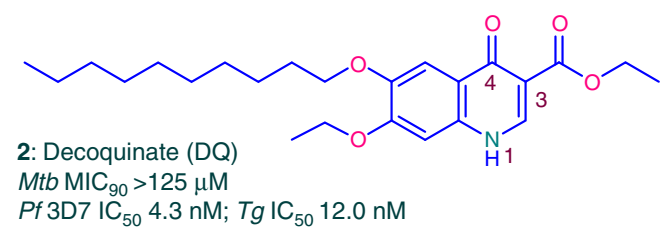

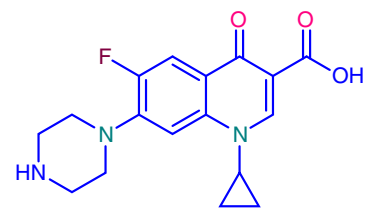

Ciprofloxacin Mtb $\mathrm{MIC}_{90} 1.5-12 \mu \mathrm{M}$

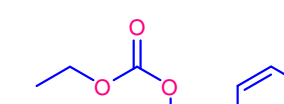<smiles>CCOC(=O)Oc1c(-c2ccc(Oc3ccc(C(F)(F)F)cc3)cc2)c(C)nc2cc(OC)c(Cl)cc12</smiles>

ELQ-337 Pf IC 50 D6 $1.4 \mathrm{nM}$ Dd2 $2.8 \mathrm{nM}$
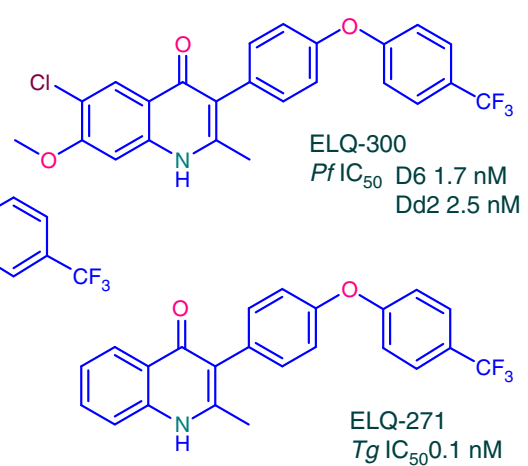

Fig. 1 Biologically active quinolones. The $4(1 H)$-quinolone scaffold $\mathbf{1}$, the fluoroquinolone ciprofloxacin active against TB (ref. ${ }^{20}$ ), the endochin analogue EQ-300 and the quinoline O-carbonate prodrug ELQ-337 active against malaria (refs. ${ }^{23,24}$ ), and ELQ-271 active against toxoplasmosis (ref. ${ }^{27}$ ). Activity of decoquinate 2 against $M t b$ is unrecorded, but is active against malaria (refs. ${ }^{31,32}$ ) and toxoplasmosis (ref. ${ }^{33}$ ). Activities of the quinolones in vitro against Mtb, Pf and Tg are given. Pf 3D7 and D6 are chloroquine (CQ)-sensitive, W2 and Dd2 are CQ-resistant strains 


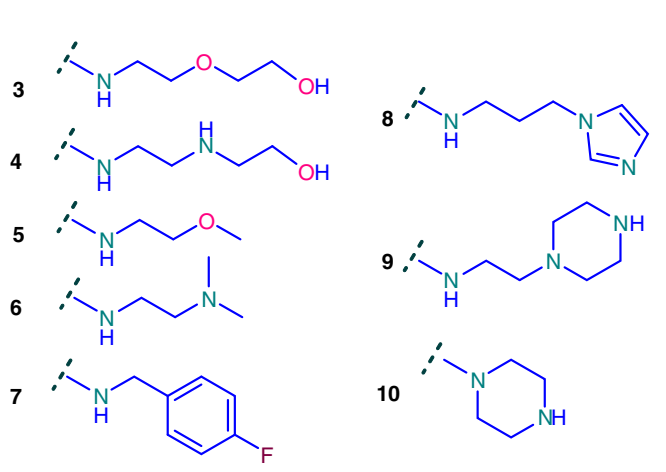<smiles>CC=C(C)CCCC</smiles>

$16 \therefore{ }_{\mathrm{H}} \curvearrowright \mathrm{OH}$<smiles>CCNCCNCCO</smiles>

$18 \therefore$

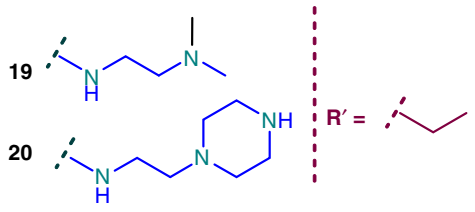

11-20: $N$-alkyl DQ amides

3-10: DQ amides<smiles>CCOc1cc2[nH]cc(C(=O)F)c(=O)c2cc1OC</smiles><smiles>C#CC#N</smiles><smiles>[R7]Oc1c(C(=O)OCC)cnc2cc(OCC)c(OCC)cc12</smiles>

21,22: Quinoline ethyl ester carbamates

$\mathbf{R}^{\prime \prime}=$<smiles>CCC(=O)N1CCOCC1</smiles><smiles>CC(C)C(=O)N1CCN(S(C)(=O)=O)C1=O</smiles><smiles>[R7]Oc1c(C(=O)OCCOC)cnc2cc(OCC)c(OCCC)cc12</smiles><smiles>[R7]Oc1c(C([R])=O)cnc2cc(OCC)c(OCC)cc12</smiles>

23,24: Quinoline methoxyethyl ester carbamates carbamates $\mathbf{R}^{\prime \prime}=$<smiles>CCN1CCN(C(C)=O)C(=O)C1=O</smiles><smiles>[Z4]C(=O)N1CCN(S(C)(=O)=O)C1=O</smiles>

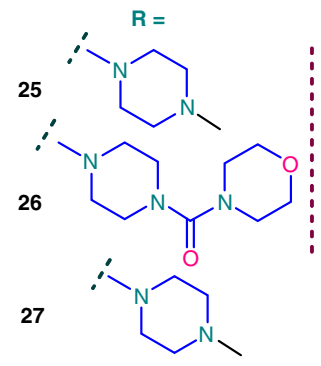

$\mathbf{R}^{\prime \prime}$<smiles>CS(=O)(=O)N1CCN(C(=O)I)C1=O</smiles>

Fig. 2 Derivatives obtained from decoquinate 2. i. $1^{\circ}$ or $2^{\circ}$ amine, 1,8-diazabicyclo[5.4.0]undec-7-ene (DBU), $\mathrm{CHCl}_{3}, \mathrm{reflux}, 24-72 \mathrm{~h}$ (ref. ${ }^{38}$ ); ii. $1^{\circ} \mathrm{Alkyl}$ halide, $\mathrm{K}_{2} \mathrm{CO}_{3}, \mathrm{DMF}, 10 \mathrm{~h}$; iii. Carbamoyl chloride, $\mathrm{DBU}, \mathrm{CHCl}_{3}$, reflux, $15 \mathrm{~h}$; iv. 2-Methoxyethanol, conc. $\mathrm{H}_{2} \mathrm{SO}_{4}, \mathrm{CHCl}_{3}$, reflux, 72 h; $\mathrm{R}=$ amine component of $2^{\circ}$ or $3^{\circ}$ amide; $\mathrm{R}^{\prime}=$ alkyl group; $\mathrm{R}^{\prime \prime}=$ carbamoyl<smiles>[R]POc1c(C(=O)OC)cnc2cc(OCC)c(OC)cc12</smiles>

Fig. 3 Regiochemistry of reactions of the pyridone anion. Deprotonation of the 4-pyridone system in DQ $\mathbf{2}$ generates the pyridone anion that as an ambident nucleophile may react through $\mathrm{N}-1$ or $\mathrm{O}-4$. For $\mathrm{S}_{\mathrm{N}} 2$-reactive electrophiles $1^{\circ}$ alkyl halides $R^{\prime} X$, lower activation free energies are associated with reaction through $\mathrm{N}-1$ leading to the $\mathrm{N}$-1-alkyl 4-pyridone (ref. ${ }^{41}$ ). However, $\mathrm{O}$-alkylation is preferred for $\mathrm{S}_{\mathrm{N}} 1$-reactive electrophiles, and carbonyl electrophiles, e.g. acyl halides, that react via additionelimination ( $R^{\prime \prime} X=$ activated alkyl or acyl halide) through O-4. Treatment of DQ with the carbamoyl chloride and DBU (route iii in Fig. 2) generated the quinoline ethyl ester carbamates 21 and 22. Transesterification of DQ with methoxyethanol (route iv in Fig. 2) gave the intermediate methoxyethyl ester that on treatment with carbamoyl chloride (route iii in Fig. 2) gave the quinoline carbamates $\mathbf{2 3}$ and 24. Finally, DQ was submitted to aminolysis and the amides were treated with the carbamoyl chlorides and DBU to generate the quinoline carbamates 25-27. For the analogues lacking the decyl side chain, each of aniline, 4-chloroaniline and 3,4-dimethoxyaniline was condensed with diethyl ethoxymethylenemalonate, and the intermediate acrylamide cyclized to the 2carbethoxyquinolone ${ }^{44-46}$. Aminolysis then gave the products 28-33 (Fig. 4).

NMR spectroscopy. Because of the regiochemical issue associated with the reaction of the 4-pyridone anion in DQ with electrophiles (Fig. 3), unambiguous identification of the products is 


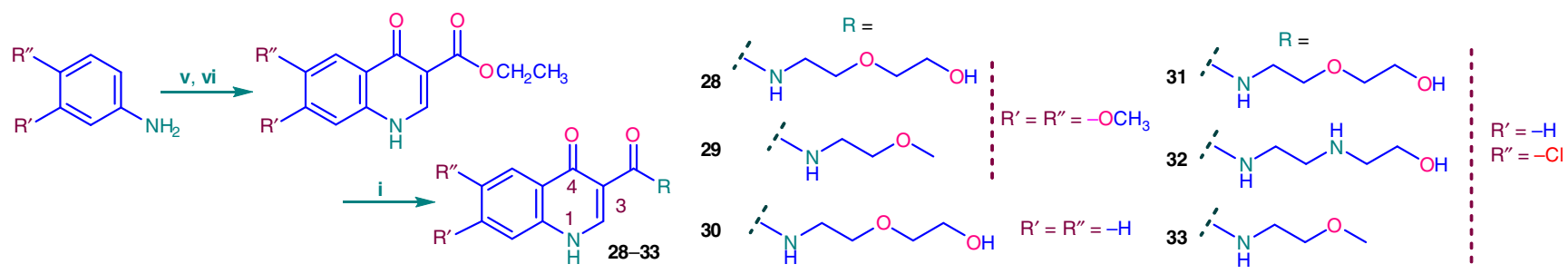

Fig. $4 \mathrm{DQ}$ chain-shortened amide analogues: v. Diethyl ethoxymethylenemalonate, acetonitrile, reflux, $10 \mathrm{~h}$; vi. Eaton's reagent, $\mathrm{N}_{2}, 70^{\circ} \mathrm{C}, 10 \mathrm{~h}$; i. as route 1 in Fig. 2. $1^{\circ}$ amine, $\mathrm{DBU}, \mathrm{CHCl}_{3}$, reflux, 24-72 $\mathrm{h}$

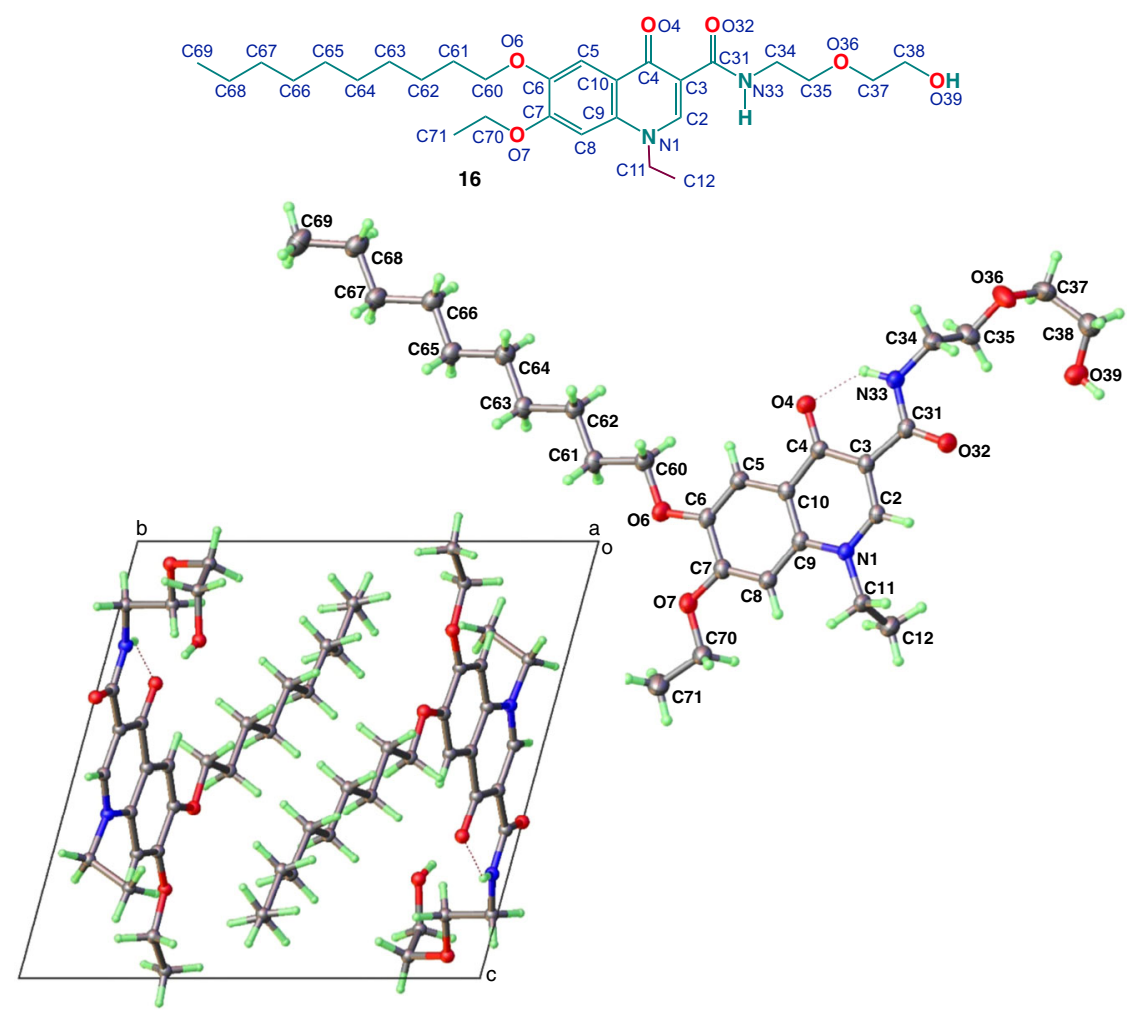

Fig. 5 X-ray crystallographic determination of structure of compound 16. Crystallographic numbering for 16, ORTEP plot with $50 \%$ probability displacement ellipsoids, and packing diagram viewed along the $a$-axis showing antiparallel arrangement of the $n$-decyl chains

required. Although 2D NMR spectroscopy has been used in related systems for this purpose ${ }^{47,48}$, structural assignments to the DQ derivatives are markedly complicated by the saturated decyloxy side chain. Thus, the $N$-ethyl DQ amide 16 (Fig. 4b) and the quinoline ester carbamate $\mathbf{2 2}$ (Fig. 2) were examined by $2 \mathrm{D}$ NMR spectroscopy using correlation (COSY), total correlation (TOCSY), nuclear Overhauser effect (NOESY), heteronuclear multiple-bond correlation (HMBC) and heteronuclear singlequantum correlation spectroscopy (HSQC, gHSQCAD) edited to provide $\mathrm{CH}_{2}$ signals in opposite phase to $\mathrm{CH}_{3}$ and $\mathrm{CH}$ signals. For 22, signals were also assigned by comparing with data in the Spectral Database for Organic Compounds ${ }^{49}$. The methods together are discussed in detail in the Supplementary Methods and ${ }^{1} \mathrm{H}$ and ${ }^{13} \mathrm{C}$ chemical shifts and assignments to compounds 16 and 22 are given in Supplementary Tables 1 and 2. Signals in the ${ }^{1} \mathrm{H}$ NMR spectra of the other derivatives could now be assigned as set out in the Supplementary Methods; these allow for clear differentiation between the structural type$\mathrm{s}$ of Fig. 2. The constitution of all compounds was also confirmed by high-resolution mass spectrometry. All compounds had greater than $95 \%$ purity as assessed by analytical HPLC. These were more soluble in common organic solvents such as ethanol, acetone or dimethyl sulfoxide and less lipophilic $(c \log P<8)$ than DQ. Full details of spectroscopic data including high-resolution mass spectrometric data are given in the Supplementary Methods.

X-ray crystallography. For structural proof and to obtain information required for eventual molecular modelling associated with putative biological targets, crystalline samples of the DQ amide $\mathbf{1 6}$ and the quinoline carbamate $\mathbf{2 2}$ were sought for X-ray structure determination. Crystal growth conditions for amide $\mathbf{1 6}$ were eventually established by solvent layer diffusion of hexane into a saturated acetone solution at ambient temperature wherein fine colourless needle-like crystals were obtained. Although carbamate 22 recrystallized easily from protic solvents such as ethanol, it was not possible to obtain sufficiently large crystal specimens by layering methods or by controlled evaporation via solvent vapour diffusion, although a microcrystalline sample was prepared from ethyl acetate in the latter manner. A single needle specimen of $\mathbf{1 6}$ with dimensions $0.35 \times 0.06 \times 0.02 \mathrm{~mm}$ was protected by immersion in Paratone and mounted in a Cryoloop on a RigakuOxford Diffraction Supernova diffractometer equipped with copper micro-source and Atlas detector. X-ray diffraction 
intensity data were collected at $-100{ }^{\circ} \mathrm{C}$ to a 2-theta maximum of $135^{\circ}$ (Cu-Ka radiation). The structure of $\mathbf{1 6}$ (Fig. 5) was solved by the charge-flipping algorithm of Olex-solve, refined using full matrix least squares with anisotropic nonhydrogen atoms and in the Olex2 X-ray structure program suite ${ }^{50,51}$. The quinolone unit has all four substituents disposed in the molecular plane. The amide substituent at $\mathrm{C}(3)$ is coplanar with the ring and oriented so that the $\mathrm{C}(31)=\mathrm{O}(32)$ is in an anti-orientation with respect to the quinolone keto group $\mathrm{O}(4)$. This places the amide $\mathrm{N}(33) \mathrm{H}$ in an orientation to make a weak incipient intramolecular hydrogen bond to $\mathrm{O}(4)$. The pendant alcohol $\mathrm{O}(39)-\mathrm{H}$ also forms an intermolecular hydrogen bond to $\mathrm{O}(4)$ of a neighbouring molecule displaced along the $a$-axis. $\mathrm{O}(39)--\mathrm{O}(4)=2.743(2) \AA$. The decyl group has a regular all-trans-torsional arrangement and this aligns in the molecular packing with symmetry inverted neighbours to give efficient packing of the distinctly antiparallel decyl chains (Fig. 5). Another key packing feature is that considerable pair-wise $\pi-\pi$ interaction occurs between the quinolone ring and its a-displaced antiparallel neighbour. Details of the X-ray methods and structural summary are given in the Supplementary Methods and Supplementary Table 3. The CIF files appear in Supplementary Data 1.

Activities against tuberculosis and preliminary mechanism of action. Compounds were screened against Mycobacterium tuberculosis $(M t b)$ H37Rv::gfp, an engineered reporter strain that constitutively expresses green fluorescent protein (GFP), in a broth microdilution assay with rifampicin as a reference. As detailed previously ${ }^{52}$, assays were performed in the glycerol-based GAST-Fe medium. Activities are reported as minimum inhibitory

\begin{tabular}{|c|c|c|c|c|c|}
\hline \multirow[t]{2}{*}{ Compound $^{\mathrm{a}}$} & \multirow[t]{2}{*}{ CLogPb } & \multicolumn{2}{|c|}{ Mtb H37Rv } & \multirow{2}{*}{$\begin{array}{l}\text { WI- } \\
38 \\
I C_{50} \\
(\mu M)^{c}\end{array}$} & \multirow{2}{*}{$\begin{array}{l}\text { Selectivity } \\
\text { index SI }\end{array}$} \\
\hline & & $\begin{array}{l}\text { MIC }_{90} \\
(\mu \mathrm{M})\end{array}$ & $\mathrm{MIC}_{99}(\mu \mathrm{M})$ & & \\
\hline RIF & ND & 0.00315 & 0.00386 & ND & ND \\
\hline DQ 2 & 8.0 & $>125$ & $>125$ & $>125$ & ND \\
\hline 3 & 6.0 & 17.5 & 21 & 43.9 & 2.5 \\
\hline 4 & 5.9 & 18 & 34.4 & $>100$ & $>5.5$ \\
\hline 5 & 6.8 & 33.9 & 64.9 & 48.7 & 1.4 \\
\hline 6 & 7.2 & 19 & 22.1 & 13.3 & 0.7 \\
\hline 7 & 8.0 & $>125$ & $>125$ & ND & ND \\
\hline 8 & 6.8 & 38.3 & 49 & 3.08 & 0.08 \\
\hline 9 & 6.7 & 10.5 & 14.5 & $>100$ & $>9.5$ \\
\hline 10 & 6.5 & 22.9 & 36.9 & 5.88 & 0.3 \\
\hline 11 & 5.5 & 72.3 & 81.3 & 54.9 & 0.7 \\
\hline 12 & 5.3 & 6.46 & 8.67 & 41.3 & 6.4 \\
\hline 13 & 6.2 & 6.07 & 7.92 & 32.4 & 5.4 \\
\hline 14 & 6.1 & 12.40 & 17.90 & 70.6 & 5.7 \\
\hline 15 & 3.8 & 1.44 & 1.88 & $>100$ & $>69.4$ \\
\hline 16 & 4.9 & 1.25 & 1.61 & 56.2 & 45.0 \\
\hline 17 & 4.7 & 3.64 & 4.16 & 40.1 & 11.0 \\
\hline 18 & 5.6 & 8.00 & 18.90 & 83.4 & 10.4 \\
\hline 19 & 6.0 & 12.10 & 16.5 & 49.1 & 4.1 \\
\hline 20 & 5.6 & 8.50 & 10.80 & 37.8 & 4.4 \\
\hline 22 & 3.8 & $>125$ & $>125$ & $>100$ & ND \\
\hline 25 & 3.9 & 3.32 & 4.89 & 36.2 & 10.9 \\
\hline EM & ND & ND & ND & 0.05 & ND \\
\hline
\end{tabular}

ND not determined

aRIF Rifampicin, DQ decoquinate, EM emetine; all other compounds (Figs. 2, 4) possess $M C_{90}$ values $>125 \mu \mathrm{M}$

${ }^{\mathrm{c}} \mathrm{L}$ ogP values calculated with $\mathrm{ACD} / \mathrm{ChemSketch}$ Version 14.02

CHuman fetal lung fibroblasts WI-38 cell line (HFLF)

dSI Selectivity index $=I_{50} / \mathrm{MIC}_{90}$ concentration (MIC) values; these are determined by quantitative fluorescence and presented as the compound concentrations which inhibit the fluorescence signal by $90 \%\left(\mathrm{MIC}_{90}\right)$ or $99 \%$ $\left(\mathrm{MIC}_{99}\right)$ relative to the untreated bacillary control at day 14 postinoculation. Data are in Table 1. DQ was inactive against $M t b$. In contrast, 21 of the derivatives exhibited antimycobacterial activity, the most potent being the $N$-ethyl DQ amides 15-17 (Fig. 2); $\mathrm{MIC}_{99}$ values ranged from $1.25 \mu \mathrm{M}$ for $\mathbf{1 6}$ to $3.64 \mu \mathrm{M}$ for 17. The $N$-propyl counterpart 11 of compound 16 and the other $\mathrm{N}$-propyl quinolones were less active, and the quinoline carbamates even less so, with the quinoline ethyl ester carbamate $\mathbf{2 2}$ displaying an $\mathrm{MIC}_{99}$ of $>125 \mu \mathrm{M}$. Replacement of the ethyl ester with an amide in the latter compounds restored relatively good anti- $M t b$ activity: the quinoline amide carbamate 25 possessed an $\mathrm{MIC}_{99}$ of $4.89 \mu \mathrm{M}$. In notable contrast, the analogues 30-35, wherein the ethoxy and decyloxy chains of DQ were replaced with less bulky units (Fig. 4) were inactive against Mtb H37Rv (e.g. $3 \mathrm{MIC}_{90} 17.5 \mu \mathrm{M}$, cf. 30, $\mathrm{MIC}_{90}>125 \mu \mathrm{M}$ ). Most of the decoquinate derivatives exhibited low to moderate cytotoxicities against the normal human fetal lung fibroblast WI-38 cell line with $\mathrm{IC}_{50}$ values greater than $30 \mu \mathrm{M}$ (Table 1 ).

Compounds 15-17 were tested in assays designed to provide an early indication of the potential target. The first utilizes an $M$. tuberculosis cytochrome bd oxidase deletion mutant cydKO, which is hypersusceptible to compounds such as imidazopyridines that target the QcrB subunit of the qcrCAB-encoded cytochrome $b c_{1}$ complex ${ }^{53-55}$. No hypersensitivity was observed when the cydKO mutant was tested against 15-17. Similarly, there was no MIC shift observed when the compounds were tested against a derivative of the cydKO mutant carrying an additional Ala317Thr point mutation in $q c r B^{53}$, supporting the notion that $\mathrm{QcrB}$ does not constitute the primary target. These results were confirmed for compound $\mathbf{1 6}$ using the XF96 Extracellular Flux Analyser ${ }^{56}$, in which the change in oxygen consumption rate (OCR) following the addition of a compound to bacterial cultures is determined at three different concentrations. Notably, no significant change in the OCR was observed following treatment with $\mathbf{1 6}$, also reinforcing the notion that QcrB is not the primary target (Supplementary Methods and Supplementary Figure 1). Bioluminescence reporter assays ${ }^{57}$ were used to establish if the compounds 15-17 disrupt cell wall homoeostasis or are genotoxic in $M t b$. All three compounds elicited a strong signal using the PiniB-LUX reporter (Supplementary Figure 2), triggering an immediate luminescence signal on day 1 which was sustained throughout the 10 -day assay, as was observed for the isoniazid control. This indicates that an aspect of cell wall metabolism constituted the primary target. When tested against the DNA damage reporter PrecA-LUX, the compounds did not elicit a signal above background for the first 4 days of the assay (Supplementary Figure 2). Interestingly, however, at days 7 and 10, a definite luminescence signal was detected, suggesting that DNA metabolism might constitute a secondary or downstream target. A similar phenotype has been observed with 5fluorouracil ${ }^{58}$.

Activities against apicomplexan parasites. For the malaria parasite Plasmodium falciparum $(P f)$, the DQ derivatives with artemether, artesunate, and chloroquine as reference drugs were assayed against drug-sensitive Pf NF54 and drug-resistant K1 and W2 intraerythrocytic asexual parasites using the SYBR Green I fluorescence proliferative readout ${ }^{59}$. The DQ amides ${ }^{38}$ and the $N$ alkyl DQ amides 11-18 active against $M t b$ (Table 1) show weak or no significant activity against $P f$ in comparison with DQ, the reference drugs and the quinoline ester derivatives (Table 2). Likewise, the chain shortened amide analogues 28-33 (Fig. 4) 
Table 2 In vitro antimalarial activities and cytotoxicities of DQ derivatives (determined by SYBR Green I fluorescence viability readout, data from three independent biological replicates, $n=3$, each performed in technical triplicates, \pm SE)

\begin{tabular}{|c|c|c|c|c|c|c|c|c|}
\hline \multirow[t]{2}{*}{ Compd } & \multirow[t]{2}{*}{ cLogP } & \multicolumn{3}{|l|}{$I C_{50}(n M)^{a}$} & \multicolumn{2}{|c|}{$\begin{array}{l}\text { Resistance } \\
\text { index }^{\mathbf{b}}\end{array}$} & \multirow[t]{2}{*}{$I C_{50}(\mu M) W I-38^{c}$} & \multirow[t]{2}{*}{ Selectivity index $\mathrm{SI}^{\mathrm{d}}$} \\
\hline & & NF54 & K1 & W2 & $\mathbf{R} \mathbf{I}_{\mathbf{1}}$ & $\mathbf{R} \mathbf{I}_{\mathbf{2}}$ & & \\
\hline ARM & ND & $5.77 \pm 1.33$ & $7.26 \pm 2.34$ & $4.5 \pm 0.78$ & 1.3 & 0.8 & ND & ND \\
\hline ARS & ND & $7.88 \pm 1.35$ & $8.97 \pm 2.26$ & $6.77 \pm 1.13$ & 1.4 & 0.8 & $>100$ & $>12,690$ \\
\hline CQ & ND & $510 \pm 3.8$ & $154.7 \pm 14.9$ & $233.18 \pm 49$ & 15.0 & 22.6 & ND & ND \\
\hline DQ 2 & 8.19 & $26.6 \pm 1.4$ & $64.9 \pm 8.8$ & $15.4 \pm 3.4$ & 2.4 & 0.6 & $>100$ & $>3759$ \\
\hline 11 & 5.5 & $>200$ & $>200$ & $>200$ & ND & ND & 54.9 & ND \\
\hline 12 & 5.3 & $156.9 \pm 10.6$ & $197.7 \pm 41.4$ & $194.5 \pm 48.3$ & 1.3 & 1.2 & 41.3 & 263 \\
\hline 17 & 4.7 & $>200$ & $>200$ & $>200$ & ND & ND & 40.1 & ND \\
\hline 18 & 5.6 & $>200$ & $>200$ & $>200$ & ND & ND & 83.4 & ND \\
\hline 21 & 5.0 & $6.8 \pm 3.9$ & $14.4 \pm 6.3$ & $5.7 \pm 3.5$ & 2.0 & 0.8 & $>100$ & $>14,705$ \\
\hline 22 & 3.8 & $1.4 \pm 0.5$ & $1.3 \pm 0.6$ & $1.1 \pm 0.1$ & 0.9 & 0.7 & $>100$ & $>71,428$ \\
\hline 23 & 3.5 & $93.1 \pm 35.4$ & $80.5 \pm 34.1$ & $47.1 \pm 2.9$ & 0.8 & 0.5 & $>100$ & $>1074$ \\
\hline 24 & 2.9 & $9.6 \pm 2.9$ & $15.0 \pm 5.6$ & $7.4 \pm 1.9$ & 1.5 & 0.7 & $>100$ & $>10,416$ \\
\hline 25 & 5.2 & $136.0 \pm 41.9$ & >200 & $84.4 \pm 28.1$ & 2.0 & 0.6 & $>100$ & $>735$ \\
\hline 26 & 3.2 & $92.1 \pm 49.3$ & $65.35 \pm 22.3$ & $19.8 \pm 1.2$ & 1.2 & 0.2 & 40.1 & 435 \\
\hline 27 & 2.7 & $21.9 \pm 11.7$ & $16.8 \pm 5.9$ & $9.1 \pm 1.1$ & 0.7 & 0.4 & 56.5 & 2579 \\
\hline Emetine & ND & ND & ND & ND & ND & ND & 0.05 & ND \\
\hline
\end{tabular}

\begin{tabular}{|c|c|c|c|c|c|}
\hline \multirow[t]{2}{*}{ Compound } & \multicolumn{3}{|c|}{$I C_{50}(n M)^{a}$} & \multicolumn{2}{|c|}{ Resistance index } \\
\hline & NF54 & K1 & $\begin{array}{l}\text { TM90- } \\
\text { C2B }\end{array}$ & $\mathbf{R I}_{1}$ & $\mathbf{R I}_{\mathbf{2}}$ \\
\hline Artesunate & 1.3 & 0.58 & 1.1 & 0.45 & 0.85 \\
\hline Chloroquine & 3.6 & 60 & 58 & 16.67 & 16.11 \\
\hline Atovaquone & 0.14 & 0.20 & 11,536 & 1.4 & 82,400 \\
\hline 22 & 0.53 & 0.56 & 111.9 & 1.06 & 211.13 \\
\hline
\end{tabular}

apf NF54: CQ sensitive; K1: CQ, pyrimethamine, mefloquine, cycloguanil resistant; TM90-C2B: atovaquone resistant

$\mathrm{b}_{\mathrm{RI}_{1}}=\mathrm{IC}_{50} \mathrm{~K} \mathrm{~K} / \mathrm{IC} \mathrm{C}_{50} \mathrm{NF54}, \mathrm{RI}_{2}=\mathrm{IC}_{50} \mathrm{TM} 90-\mathrm{C} 2 \mathrm{~B} / \mathrm{IC}_{50} \mathrm{NF54}$

when applied at $1 \mu \mathrm{M}$ to CQ-sensitive Pf NF54 cultures showed poor activities in vitro with $<50 \%$ growth inhibition. Although DQ displays good activities, the quinoline ester carbamates 21 and 22 (Fig. 2) are appreciably more reactive, and are approximately equipotent with artemether and artesunate (Table 2), widely regarded as among the most efficacious of antimalarial drugs. Compounds 22, 23, and 27 all have resistance indices $<1$, indicating that they display higher activities against multidrugresistant than CQ-sensitive Pf strains.

Activity of the best compound $\mathbf{2 2}$ with chloroquine, artesunate, and atovaquone as comparator drugs was assessed against asexual blood stages of Pf NF54 and K1 (see above) and TM90-C2B resistant to atovaquone using an assay that measures parasite replication in erythrocytes by incorporation of $\left[{ }^{3} \mathrm{H}\right]$-hypoxanthine into parasite $\mathrm{DNA}^{60}$; this assay thus uses a different readout to the above method (Table 3 and Supplementary Methods). Both assay methods indicate that compound 22 displays no cross-resistance with CQ-resistant strains. As noted above, quinolones act against the $P f$ cytochrome $b c_{1}$ complex and display cross-resistance with atovaquone-resistant $P f^{25,61}$; for DQ, this is attributed to partial binding within the ubiquinol-binding site carrying one or more of the resistance mutations $\mathrm{s}^{30}$. Thus, according to Table 3, cross-resistance is also observed for the DQ derivative 22. It is nevertheless anticipated that such an issue will not be of consequence once combinations of one or more of these or newer derivatives with artemisinins that do not display crossresistance with atovaquone-resistant parasites (cf. Table 3) are developed.

In relation to potential for blocking transmission of parasites from human to mosquito, whereas DQ 2 showed no inhibition (cf. ref. ${ }^{31}$ ), compounds 21, 22, and 24 showed $20-40 \%$ inhibition of gametocyte viability when treated at $1 \mu \mathrm{M}$ against early (I-III) and late-stage (IV-V) Pf NF54 gametocytes, activities similar to those of atovaquone ${ }^{62}$ (Supplementary Methods and Supplementary Figure 3). Thus, these compounds are less active as transmission blocking agents than endochin-like quinolones such as ELQ-300 (Fig. 1) that arrest development of late-stage gametocytes at $1 \mu \mathrm{M}^{25}$. Nevertheless, we describe elsewhere that newer artemisinins and redox active drugs to be used in combination with the quinolones are potently active in this regard $^{17}$.

Compounds were tested in vitro for causal prophylactic effect against $P$. berghei sporozoites expressing luciferase in a liver stage malaria model ${ }^{63}$. Dose response analyses of compound 22 in 12point titrations starting from 50,10 , and $2.5 \mu \mathrm{M}$ showed that $\mathbf{2 2}$ maintained $100 \%$ inhibition of liver stage parasites down to 0.01 $\mu \mathrm{M}$ (Supplementary Figure 4) and was 154-fold and $~ 2$-fold more potent respectively than puromycin and atovaquone. To establish the parasite selectivity of this compound in the liver stage of infection, cytotoxicity was determined by measuring bioluminescence from the reaction between free ATP of compound-treated, uninfected hepatocytes and a luciferase reporter system. The average maximum hepatocyte inhibition of compound 22 was $28.7 \pm 11.2 \%$, with no measurable $\mathrm{IC}_{50}$ up to $50 \mu \mathrm{M}$ (Table 4). Thus, as in the above cases, compound $\mathbf{2 2}$ is highly selective for the malaria parasite. In comparison, in a related screening protocol using GFP-expressing liver stage sporozoites infecting the human hepatocellular carcinoma Huh7 cell line, DQ 2 itself expresses an activity of $2.6 \mathrm{nM}^{31}$. 


\begin{tabular}{|c|c|c|c|}
\hline Compound & $I C_{50}(n M)$ & $\begin{array}{l}\text { Maximum inhibition } \\
\%\end{array}$ & $\begin{array}{l}\text { HepG2 IC } \text { IO }_{50} \\
(\mu M)\end{array}$ \\
\hline Artemether & $>10^{4}$ & 49.4 & ND \\
\hline Atovaquone & $0.616 \pm 0.014$ & 80.4 & $>0.250 \pm 0$ \\
\hline Puromycin & $\begin{array}{l}48.55 \pm \\
0.071\end{array}$ & 92.6 & $0.138 \pm 0.018$ \\
\hline 22 & $\begin{array}{l}0.316 \pm \\
0.020\end{array}$ & 104 & $>50.0 \pm 0$ \\
\hline
\end{tabular}

\begin{tabular}{|c|c|c|c|}
\hline Compound & $\begin{array}{l}\text { T. gondii IC } \mathrm{C}_{50} \\
(\mathrm{nM})\end{array}$ & $\begin{array}{l}\text { N. caninum } \mathrm{IC}_{50} \\
(\mathrm{nM})\end{array}$ & HFF IC $\mathrm{C}_{50}(\mathrm{nM})$ \\
\hline 22 & $1.1(0.9-1.4)$ & $0.6(0.2-1.8)$ & $\begin{array}{l}4100 \\
(3600-4700)\end{array}$ \\
\hline 23 & $15(8-25)$ & $18(14-22)$ & $>10,000^{a}$ \\
\hline 24 & $9(7-11)$ & $8.4(8.0-8.7)$ & $>10,000^{a}$ \\
\hline BKI-1294b & $137(129-145)$ & $32(27-37)$ & $>10,000^{a}$ \\
\hline
\end{tabular}

For the other apicomplexan parasites Toxoplasma gondii $(\mathrm{Tg})$ and Neospora caninum ( $N c)$, DQ 2, the $N$-alkyl DQ amides 12 and 19, the quinoline ester carbamates 21-24, the quinoline amide carbamates 26 and 27 and others were tested in vitro against $\mathrm{Tg}$ and $\mathrm{Nc}$ beta-galactosidase reporter strains grown in human foreskin fibroblasts (HFF) ${ }^{64,65}$. Prescreening at concentrations of 1000,100 , and $10 \mathrm{nM}$ enabled preselection of compounds 22-24. Next, proliferation of $\mathrm{Tg}$ and $\mathrm{Nc}$ was tested in the presence of a concentration series of these compounds ranging from 0 to $20 \mathrm{nM}$. Toxicity against HFF host cells was determined using the Alamar Blue vitality test with a concentration series ranging from 0 to $10 \mu \mathrm{M}$. $\mathrm{IC}_{50}$ values and error margins were determined after logit-log-transformation of the respective values corrected for blanks. The data are summarized in Table 5. The compounds are appreciably more reactive than the bumped kinase inhibitor BP-1294, a pyrazolopyrimidine that inhibits calcium-dependent protein kinases of these parasites ${ }^{65}$. With respect to cytotoxicities against host HFF cells, compounds 22-24 were highly selective for the parasites. According to Table 2, the compounds displayed negligible cytotoxicities towards the human fetal lung fibroblasts WI-38 cell line, with $\mathrm{IC}_{50}$ values $>100 \mu \mathrm{M}$.

Assessment of cytotoxicities. The sulforhodamine B (SRB) assay was used to assess cytotoxicities against the normal human fetal lung fibroblast WI-38 cell line (HFLF WI-38) with emetine as standard. Activities are reported as $\mathrm{IC}_{50}$ values-the concentration required to reduce the viability of the cell line by $50 \%$. The selectivity index (SI) is obtained by dividing the $\mathrm{IC}_{50}$ value by the $\mathrm{MIC}_{90}$ value for the mycobacterial assays and by the $\mathrm{IC}_{50}$ value for antimalarial activities. The biological activities of the compounds are in Tables 1,2 . The most active antimycobacterial compounds 15-17 had selectivity indices 11-69 (Table 1) representing an acceptable margin for carrying forward the compounds for development as TB drugs. For the apicomplexan parasites, DQ and the active compounds showed no appreciable toxicity to mammalian WI-38 cells.

\section{Discussion}

It is notable that the quinolone amide analogues 28-33 (Fig. 4) lacking the lipophilic decyloxy side chain of the DQ amides (Fig. 2) were inactive against $M t b$. This vindicates the premise that one or more lipophilic side chains corresponding at least to the decyloxy side chain of DQ is a prerequisite for the development of new quinolones with antimycobacterial activities. It is further noted that the DQ amides 3, 4, 6, and 9 containing ethanolamino- or ethylenediamino-linked amide side chains elicit activities superior to the other DQ amides. In contrast, all such compounds are essentially inactive against malaria. The most active DQ amides 15-17 additionally contain an alkyl group attached to N-1. For mechanism of action of these compounds against $M t b$, the results obtained from triage assays ${ }^{53,54}$, the lack of hypersensitivity observed in a cydKO mutant, and measurement of OCR eliminate mycobacterial respiration as target. In contrast, the immediate and sustained luminescence signal in the PiniB-LUX reporter assay strongly implicates cell wall homoeostasis as a likely primary target ${ }^{57}$. Moreover, the detection of late-stage (after day 4) triggering of $r e c A$ promoter activity suggests some effect on DNA metabolism as well. In some respects, this is similar to the polypharmacology profile of 5 -fluorouracil ${ }^{57}$. Further work is required to determine the precise mechanism, and will focus initially on DprE1 ${ }^{66}$ and MmpL $3^{67}$ given the frequency with which these have been identified in other in vitro screens for potential antimycobacterial compounds ${ }^{68}$. To summarize, the $N$-alkyl DQ amide derivatives $15-17$ are easily accessible, with 16 being approximately equipotent in vitro with the fluoroquinolones ciprofloxacin ( $\mathrm{MIC}_{90} 1.5-12 \mu \mathrm{M}$, Fig. 1), gatifloxacin $(0.66-1.3 \mu \mathrm{M})$ and moxifloxacin $(0.62-1.3 \mu \mathrm{M})$ used clinically against $\mathrm{TB}^{20}$. Overall, the selectivities and novel mode of action with respect to disruption of cell wall homoeostasis indicate that these accessible quinolones have the potential to supplement other drugs for treatment of TB.

For malaria, even though in contrast to DQ, the $N$-alkyl DQ amide derivatives $\mathbf{1 1}, \mathbf{1 2}, \mathbf{1 7}$, and 18 (Fig. 2) are soluble in polar solvents, these are less active in vitro than DQ (Table 2). In notable contrast, the quinoline amide carbamates 26 and 27 are approximately equipotent with, and the quinoline ester carbamates $\mathbf{2 1}, \mathbf{2 2}$, and $\mathbf{2 4}$ are substantially more active than, DQ. The compounds may be crystallized from ethanol, are stable as pure substances and are soluble in common organic solvents. It is of relevance to note that the quinoline carbonate ELQ-337 (Fig. 1) serves as a prodrug for ELQ-300 from which it is chemically derived $^{23}$. However, carbamates are expected on electronic grounds to be more stable to hydrolysis under neutral conditions than carbonates; clearly the question as to whether these compounds act as prodrugs for DQ must be resolved by assessment of pharmacokinetic parameters. In any event, the differing activities in vitro of each of $\mathbf{2 1}$ bearing a morpholino carbamoyl group and 22 bearing the more polar methanesulfonyl-imidazolidinone carbamoyl group must reflect enhanced uptake for the latter compound. Overall, the compounds 21, 22, and 24 that are economically obtained in one chemical step from DQ display in vitro efficacies markedly superior to DQ itself. For the other apicomplexan parasites (Table 5), it is noteworthy that the quinoline ester carbamates 22-24 are the most active compounds. Overall, the best compounds 21-24, in particular compound 22, have efficacies and selectivity indices with respect to normal cell 
lines that indicate considerable potential for use as therapies against apicomplexan parasites.

It is of no small consequence that the quinolone decoquinate, itself long used for treatment of parasites that cause coccidiosis in livestock ${ }^{28,29}$, can be economically converted into derivatives that are more potent than DQ itself, or display activities against a pathogen, namely $M t b$, against which DQ appears to be inactive and wherein a principal mode of action differing to that of the antitubercular quinolones is operating. Moreover, the $\mathrm{IC}_{50}$ values for all compounds against normal human fetal lung fibroblast cell line WI-38 ranged from 40 to $>100 \mu \mathrm{M}$, indicating good selectivity for the bacterial, and in particular, for the parasite, pathogens. The overall conversion of decoquinate into two of the optimum compounds $\mathbf{1 6}$ and 22 and their biological activities are summarized in Supplementary Figure 5. The next phases of the programme involving target profile evaluation and assessment of pharmacokinetic properties coupled with the combination studies as foreshadowed in the Introduction are underway, and will be reported upon in due course.

\section{Methods}

Preparation of decoquinate derivatives and analogues. The amines, the carbamoyl chlorides, the alkyl halides, and 1,8-diazabicyclo[5.4.0] undec-7-ene (DBU) from Sigma Aldrich or AKSci were used as supplied. ${ }^{1} \mathrm{H}$ and ${ }^{13} \mathrm{C}$ NMR spectra (NWU) of the products were obtained on a $600 \mathrm{MHz}$ Bruker Avance ${ }^{\mathrm{mt}}$ III spectrometers as solutions in $\mathrm{CDCl}_{3}$, or DMSO- $d_{6}$. Chemical shifts $(\delta)$ are reported in parts per million (ppm) values. ${ }^{1} \mathrm{H}$ chemical shifts are reported downfield of tetramethylsilane, and were referenced to solvent signals in $\mathrm{CDCl}_{3}(7.26 \mathrm{ppm})$ or DMSO- $d_{6}(2.50 \mathrm{ppm}) .{ }^{13} \mathrm{C}$ chemical shifts were referenced to $\mathrm{CDCl}_{3}(\delta 77.16 \mathrm{ppm})$ or DMSO- $d_{6}(\delta 39.51 \mathrm{ppm})$. Peak multiplicities are abbreviated as follows: $\mathrm{s}$ (singlet), d (doublet), dd (doublet of doublet), t (triplet), q (quartet), and $\mathrm{m}$ (multiplet). Coupling constants $J$ are in Hz. NMR data were analysed using MestReNova Software, version 5.3.2-4936. The NMR methods (HKUST) for compounds $\mathbf{1 6}$ and $\mathbf{2 2}$ employed a Varian VNMRS-500 spectrometer, with summary of methods given in the Supplementary Methods.

Exact mass measurements were recorded on Bruker MicroTOF Q II mass spectrometer that has an APCI/ESI source set at $300^{\circ} \mathrm{C}$. A full scan, ranging between $\mathrm{m} / z 50$ and 1500 , was generated at a capillary voltage of $4500 \mathrm{~V}$, end plate offset voltage of $-500 \mathrm{~V}$, and a collision cell RF voltage of $100 \mathrm{~V}$. Melting points were determined with a Büchi melting point B-545 instrument and were uncorrected. Thin layer chromatography (TLC) was performed using Merck silica gel plates $\left(60 \mathrm{~F}_{254}\right)$, and components were visualized by ultraviolet light $(254 \mathrm{~nm})$. Silica gel 230-400 (particle size 40-63 $\mu \mathrm{m}$ ) mesh was used for column chromatography. For HPLC analyses, an Agilent 1100 instrument equipped with a gradient pump, autosampler, diode array UV detector and OpenLab CDS Chemstation Rev.C.01.07 SR3 data acquisition software was used (Agilent Technologies, Palo Alto, CA, USA). The column was a Venusil XBP C18(2) -column, $150 \times 4.6 \mathrm{~mm}, 5 \mu \mathrm{M}$ spherical particles, $100 \AA$ pore size (Agela Technologies, Newark, DE, USA). The mobile phase was acetonitrile and $0.1 \%$ $\mathrm{H}_{3} \mathrm{PO}_{4}$ acid in water with a linear gradient from $30 \%$ acetonitrile to $85 \%$ after 5 min and holding until $15 \mathrm{~min}$ before equilibrating with $30 \%$ acetonitrile to $20 \mathrm{~min}$. The flow rate was set at $1 \mathrm{~mL} /$ minute and the injection volume was $10 \mu \mathrm{L}$. The UV signal was monitored at $210 \mathrm{~nm}$.

DQ amides 3-10. A mixture comprising the $1^{\circ}$ or $2^{\circ}$ amine (5 eq.), DQ (1 g, 2.34 $\mathrm{mmol})$ and $\mathrm{DBU}(0.33 \mathrm{~g}, 320 \mu \mathrm{L}, 2.1 \mathrm{mmol}, 0.9 \mathrm{eq}$.) in chloroform $(25 \mathrm{~mL})$ was stirred under reflux for $24-72 \mathrm{~h}$. Progress of the reaction was monitored by TLC. Upon completion, the reaction mixture was concentrated by evaporation under reduced pressure. The residue was dissolved in chloroform $(20 \mathrm{~mL})$ and washed with distilled water $(4 \times 20 \mathrm{~mL})$. The organic layer was dried $\left(\mathrm{Na}_{2} \mathrm{SO}_{4}\right)$, filtered and the filtrate was evaporated to dryness to leave the crude product. This was submitted to chromatography. Elution with dichloromethane-methanol $(10: 1 \mathrm{v} / \mathrm{v})$ provided the fraction containing the product that was isolated by evaporation of solvent. The product was recrystallized from ethyl acetate. Data are given in Supplementary Methods.

$\mathbf{N}$-alkyl DQ amides 11-20. A mixture of DQ $(0.5 \mathrm{~g}, 1.19 \mathrm{mmol}, 1$ eq. $), \mathrm{K}_{2} \mathrm{CO}_{3}$ $(0.69 \mathrm{~g}, 5.0 \mathrm{mmol}$,) and the alkyl halide (5 eq.) in DMF $(10 \mathrm{~mL})$ was heated under gentle reflux for $10 \mathrm{~h}$, after which the mixture was evaporated to dryness under reduced pressure. The residue was treated with chloroform, and filtered. The filtrate was washed with distilled water $(4 \times 20 \mathrm{~mL})$. The organic phase was evaporated to dryness to obtain the crude $\mathrm{N}$-alkyl product which was used in the ensuing step without purification.

A mixture of the crude $N$-alkyl product $(0.5 \mathrm{~g}, 1$ eq.), DBU $(0.33 \mathrm{~g}, 320 \mu \mathrm{L}, 2.1$ $\mathrm{mmol})$, the amine (5 eq.), and chloroform $(15 \mathrm{~mL})$ was stirred under reflux for
24-72 h. Progress of the reaction was monitored by TLC. Upon completion, the reaction mixture was treated with additional chloroform $(20 \mathrm{~mL})$ and washed with distilled water $(4 \times 20 \mathrm{~mL})$. The organic layer was dried $\left(\mathrm{Na}_{2} \mathrm{SO}_{4}\right)$, filtered and the filtrate was evaporated to dryness to leave the crude product. This was submitted to chromatography. Elution with dichloromethane-methanol $(10: 1 \mathrm{v} / \mathrm{v})$ provided the fraction containing the product that was isolated by evaporation of solvent. The product was recrystallized from ethyl acetate. Data are given in Supplementary Methods.

Quinoline ester carbamates 21-24. To mixture of DQ ( $1 \mathrm{~g}, 2.34 \mathrm{mmol}, 1$ eq.) and 2 -methoxyethanol $(1 \mathrm{~mL}, 5$ eq. $)$ in chloroform $(20 \mathrm{~mL})$ was added conc. $\mathrm{H}_{2} \mathrm{SO}_{4}$ $(0.33 \mathrm{~g}, 320 \mu \mathrm{L}, 2.1 \mathrm{mmol}, 0.9$ eq.). The mixture was stirred under reflux for $72 \mathrm{~h}$ The reaction mixture was washed with aqueous saturated $\mathrm{NaHCO}_{3}$ solution $(3 \times$ $20 \mathrm{~mL})$. The organic layer was dried $\left(\mathrm{Na}_{2} \mathrm{SO}_{4}\right)$, filtered and the filtrate was evaporated to dryness to leave the crude product. This was submitted to chromatography on silica gel. Elution with dichloromethane-methanol $(20: 1 \mathrm{v} / \mathrm{v})$ provided the fraction containing the intermediate that was isolated by evaporation of solvent. This intermediate was used in the next step without further purification.

A mixture comprising DQ $(0.5 \mathrm{~g}$ for preparation of 21,22$)$, or the above crude product $(0.5 \mathrm{~g}$ for $23, \mathbf{2 4})$, chloroform $(15 \mathrm{~mL})$, DBU $(100 \mu \mathrm{L}, 0.7 \mathrm{mmol})$, and the carbamoyl chloride (5 eq.) was stirred under reflux for $15 \mathrm{~h}$, and then washed with saturated aqueous $\mathrm{NH}_{4} \mathrm{Cl}(3 \times 20 \mathrm{~mL})$. The organic layer was dried $\left(\mathrm{Na}_{2} \mathrm{SO}_{4}\right)$, filtered and the filtrate was evaporated to dryness to obtain the crude product which was purified by chromatography. Elution with dichloromethane-methanol $(20: 1 \mathrm{v} / \mathrm{v})$ provided the fraction containing the product that was isolated by evaporation of solvent. Derivatives 21-24 were thereby obtained in $50-80 \%$ yields. Data are given in Supplementary Methods.

Quinoline amide carbamates 25-27. The amine (5 eq.) was added to a mixture of DQ $(0.5 \mathrm{~g}, 1.19 \mathrm{mmol})$ and DBU $(0.33 \mathrm{~g}, 320 \mu \mathrm{L}, 2.1 \mathrm{mmol}, 0.9 \mathrm{eq}$.$) in chloroform$ $(25 \mathrm{~mL})$ and the mixture was stirred under reflux for $72 \mathrm{~h}$. Progress of the reaction was monitored by TLC. Upon completion, the reaction mixture was treated with additional chloroform $(20 \mathrm{~mL})$ and washed with distilled water $(4 \times 20 \mathrm{~mL})$. The organic layer was dried $\left(\mathrm{Na}_{2} \mathrm{SO}_{4}\right)$, filtered and the filtrate was evaporated to dryness to leave the crude product, which was used in the next step without further purification.

A mixture of the above crude product $(0.5 \mathrm{~g})$, chloroform $(15 \mathrm{~mL}), \mathrm{DBU}(0.7$ $\mathrm{mmol}, 100 \mu \mathrm{L}$ ), and the carbamoyl chloride (5 eq.) was stirred under reflux for $15 \mathrm{~h}$ It was then cooled and washed with saturated aqueous $\mathrm{NH}_{4} \mathrm{Cl}$ solution $(3 \times 20 \mathrm{~mL})$ The organic layer was dried $\left(\mathrm{Na}_{2} \mathrm{SO}_{4}\right)$, filtered and the filtrate was evaporated to dryness to obtain the crude product which was purified by chromatography. Elution with dichloromethane -methanol $(20: 1 \mathrm{v} / \mathrm{v})$ provided the fraction containing the product that was isolated by evaporation of solvent. Derivatives 26-29 were thereby obtained in $50-80 \%$ yields. Data are given in Supplementary Methods.

Chain-shortened DQ analogues 30-35. A solution of the 3- or-4 substituted aniline and diethyl ethoxymethylenemalonate $(1$ eq.) in acetonitrile $(10 \mathrm{~mL})$ was stirred under reflux for 5-10 h. Progress of the reaction was monitored by TLC. Upon completion, the mixture was evaporated to dryness to leave a crude product, which was dissolved in Eaton's reagent $(10 \mathrm{~mL})$ and the resultant mixture heated at $50-70{ }^{\circ} \mathrm{C}$ under nitrogen for $10-20 \mathrm{~h}$. Thereupon the mixture was cooled to room temperature and then added portionwise to saturated aqueous $\mathrm{NaHCO}_{3}$. The resulting precipitate was collected by filtration, dried overnight and subjected to aminolysis as below.

The foregoing quinoline $(0.5 \mathrm{~g})$ and DBU $(0.33 \mathrm{~g}, 320 \mu \mathrm{L}, 2.1 \mathrm{mmol})$ in chloroform $(25 \mathrm{~mL})$ was treated with the amine (5 eq.), and the resulting mixture was stirred under reflux for $24 \mathrm{~h}$. Progress of the reactions was monitored by TLC. Upon completion, the reaction mixture was treated with additional chloroform (20 $\mathrm{mL})$ and washed with distilled water $(4 \times 20 \mathrm{~mL})$. The organic layer was dried $\left(\mathrm{Na}_{2} \mathrm{SO}_{4}\right)$, filtered and the filtrate was evaporated to dryness to leave the crude product. This was submitted to chromatography. Elution with dichloromethanemethanol $(10: 1 \mathrm{v} / \mathrm{v})$ provided the fraction containing the product that was isolated by evaporation of solvent. The product was recrystallized from ethyl acetate and air dried. Data are given in Supplementary Methods.

In vitro antimycobacterial assays. The broth microdilution method was used to assess the $\mathrm{MIC}_{90}$. The procedure involves using a range of concentrations of the test compound in one 96-well microtitre plate. A culture of mutant $\mathrm{Mtb}$ (H37RvMA::gfp) strain expressing recombinant GFP off a plasmid integrated at the attB locus was grown to $\mathrm{OD}_{600}$ between 0.6 and 0.7 . This culture was diluted 1:100 in GAST/Fe medium. A total volume of $50 \mu \mathrm{L}$ of the GAST/Fe medium was added to rows $2-12$ of the plate. To row $1,640 \mu \mathrm{M}$ of the compound was added in duplicate. In addition to the test compound in row 1, other wells contained GAST/ Fe medium, 5\% DMSO, rifampicin and kanamycin as controls. From there twofold serial dilution were performed by transferring $50 \mu \mathrm{L}$ solution from each preceding row to the next ensuring that all the wells contained $50 \mu \mathrm{L}$ (the dilution was exclusively for compound containing wells from row 1, and not for controls). The plate was incubated at $37^{\circ} \mathrm{C}$ (humid conditions) for 14 days. $\mathrm{MIC}_{90}$ values were 
scored by quantitative fluorescence using a Fluostar Optima microplate reader (BMG Labtech) at 7 and 14 days postinoculation. Digital images were captured and stored.

In vitro blood stage asexual P. falciparum parasite assays. Asexual $P$. falciparum parasites were maintained in human $\mathrm{O}^{+}$erythrocytes at $37^{\circ} \mathrm{C}$ with $90 \% \mathrm{~N}_{2}$, $5 \% \mathrm{CO}_{2}$ and $5 \% \mathrm{O}_{2}$ in RPMI 1640 medium supplemented with Albumax 1. Parasite growth was determined microscopically using Giemsa-stained smears. Synchronized (>95\%) ring stage parasites were obtained using 5\% D-sorbitol (Sigma-Aldrich). Drug solutions were prepared from a $10 \mathrm{mM}$ stock solution $100 \%$ DMSO (Sigma-Aldrich) in supplemented RPMI 1640 media (final DMSO concentration $<0.1 \% \mathrm{v} / \mathrm{v}$ ). Drug-sensitive NF54 and drug-resistant K1 and W2 (chloroquine, quinine, pyrimethamine and cycloguanil) $P f$ parasites were treated using a twofold drug serial dilution for $96 \mathrm{~h}$. The dose-response ( $\mathrm{IC}_{50}$ values) of the DQ derivatives and reference drugs (Table 3) were determined using the SYBR Green I based readout for parasite proliferation ${ }^{59}$. Data analysis was performed using GraphPad Prism 6. Data are from three independent biological replicates, performed in technical triplicates.

In vitro liver stage $\boldsymbol{P}$. berghei parasite assays. A. stephensi mosquitoes infected

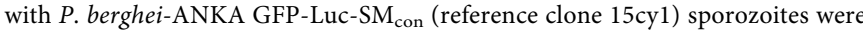
purchased from the Insectary Core at New York University. Salivary glands were dissected and suspended in cold DMEM (Invitrogen, Carlsbad, USA) before homogenization with a glass Dounce tissue grinder (Wheaton Industries). Liberated sporozoites were passed through $20 \mu \mathrm{M}$ (Millipore SCNY00020) then 11 $\mu \mathrm{M}$ (Millipore NY1104700) nylon net filters, and counted using a Neubauer hemocytometer (C-Chip, InCyto, Korea). The hepatoma cell line HepG2-A16$\mathrm{CD} 81^{\mathrm{EGFP}}$ was used for liver stage cytotoxicity and infection assays. Hepatocyte cultures were maintained using DMEM containing phenol red (Invitrogen cat\# 11965-092), 10\% FBS (Corning cat\# 35-011-CV), and $1 \times$ Pen Strep Glutamine (100 Units $/ \mathrm{mL}$ penicillin, $100 \mu \mathrm{g} / \mathrm{mL}$ streptomycin, and $0.292 \mathrm{mg} / \mathrm{mL}$ L-glutamine) (Invitrogen cat\# 10378-016). Screening assays were performed using phenol red free DMEM (Invitrogen cat\# 31053-028), 5\% FBS (Corning), and 5× Pen Strep Glutamine (Invitrogen). Both maintenance and screening were at $37^{\circ}$ $\mathrm{C}$ and $5 \% \mathrm{CO}_{2}$.

Less than $24 \mathrm{~h}$ prior to the addition of hepatocytes, $50 \mathrm{~nL}$ of compounds solubilized in DMSO (0.5\% final DMSO concentration) were stamped into empty 1536-well plates (GNF ref\#789173-F, Greiner Bio-One) using the Gen 4 Plus Acoustic Transfer System (Biosero, San Diego, USA). Dose-response titrations were made in 12-points at a 1:3 dilution ratio, with atovaquone and puromycin used as positive controls for the infected and cytotoxicity assays, respectively. DMSO $(0.5 \%)$ was used as a negative control in both assays. To each well, $3 \times 10^{3}$ of the HepG2-A16-CD81 ${ }^{\mathrm{EGFP}}$ cells were dispensed in $5 \mu \mathrm{L}$ and incubated for $24 \mathrm{~h}$ at $37^{\circ} \mathrm{C}$ and $5 \% \mathrm{CO}_{2}$. Following the dissection, purification and counting of sporozoites (spz), a solution containing $200 \mathrm{spz} / \mu \mathrm{L}$ was made in screening assay media (DMEM (Invitrogen cat\# 31053-028)), 5\% FBS (Corning), and 5× Pen Strep Glutamine (Invitrogen). Each well received $5 \mu \mathrm{L}$ of the spz solution $\left(1 \times 10^{3} \mathrm{spz} /\right.$ well). All parasite and cell solution dispensing was performed using the GNF Systems Washer/Dispenser II (GNF). Infected plates were centrifuged at $330 \times g$ for 3 min immediately after the addition of sporozoites to aid with hepatocyte invasion. In the cytotoxicity studies, $5 \mu \mathrm{L}$ of screening assay media was used only to match the volume of infected plates $(10 \mu \mathrm{L})$. All plates were then incubated for $48 \mathrm{~h}$ at $37^{\circ} \mathrm{C}$ and $5 \% \mathrm{CO}_{2}$ (high humidity).

Following the $48 \mathrm{~h}$ incubation, plates were inverted and centrifuged at $150 \times g$ for $30 \mathrm{~s}$ to remove well media. To infected plates, $2 \mu \mathrm{L}$ of BrightGlo (Promega) was dispensed into each well using the MicroFlo (BioTek) liquid handler and read immediately using the EnVision Microplate Reader (PerkinElmer). CellTiterGlo (Promega) was reconstituted and then diluted 1:2 with deionized water prior to adding $2 \mu \mathrm{L} /$ well for the cytotoxicity assay. Plates with CellTiterGlo were left out for 2 min before reading with the EnVision to allow for a plateau of the bioluminescent signal. Data analysis was performed using GraphPad Prism 7. Data points were normalized to positive and negative controls and a nonlinear regression curve was fit to determine $\mathrm{IC}_{50}$ values.

In vitro assays of $\boldsymbol{T}$. gondii and $\boldsymbol{N}$. caninum tachyzoites. Compounds were dissolved in DMSO to yield $1 \mathrm{mM}$ stock solutions. Tachyzoites of each of $T$. gondii and N. caninum NC-1 expressing E. coli beta-galactosidase were used ${ }^{65}$. Confluent HFF previously seeded into 96-well-plates were treated with the compounds or with DMSO as a control, and were infected with $10^{3}$ tachyzoites per well and incubated at $37^{\circ} \mathrm{C}, 5 \% \mathrm{CO}_{2}$. Beta-galactosidase assays were performed when the control wells were thoroughly infected, namely, after 2-3 d for $T g$, and after 3-4 d for $N c$. At these times, the medium was removed, specimens were washed with $\mathrm{PBS}$, and beta-galactosidase was assayed and $\mathrm{IC}_{50}$ values were calculated after logitlog-transformation of the original data. Toxicity against HFF host cells was determined using the Alamar Blue vitality test with a concentration series ranging from 0 to $10 \mu \mathrm{M}$.

In vitro cytotoxicity assays. The WI-38 cell line (normal human fetal lung fibroblast) from ECACC was routinely maintained as a monolayer cell culture at $37^{\circ} \mathrm{C}, 5 \% \mathrm{CO}_{2}, 95 \%$ air and $100 \%$ relative humidity in EMEM containing $10 \%$ fetal bovine serum, $2 \mathrm{mM}$ L-glutamine and $50 \mu \mathrm{g} / \mathrm{mL}$ gentamicin. For the screening experiments, the cells (21-50 passages) were inoculated in 96-well microtiter plates at plating densities of 10,000 cells/well and incubated for $24 \mathrm{~h}$. After $24 \mathrm{~h}$, the cells were treated with the compounds dissolved in DMSO and diluted in medium to produce five concentrations. Neat cells served as the control. The blank contained complete medium without cells. Parthenolide was used as a standard. The plates were incubated for $48 \mathrm{~h}$ after addition of the compounds. Viable cells were fixed to the bottom of each well with cold $50 \%$ trichloroacetic acid, washed, dried and dyed by SRB. Unbound dye was removed and protein bound dye was extracted with 10 $\mathrm{mM}$ Tris base for optical density determination at a wavelength of $540 \mathrm{~nm}$ using a multiwell spectrophotometer. Data analysis was performed using GraphPad Prism software. Fifty per cent of cell growth inhibition $\left(\mathrm{IC}_{50}\right)$ was determined by nonlinear regression.

Preparation and characterization of decoquinate derivatives and analogues. See Supplementary Methods.

\section{Data availability}

The X-ray crystallographic coordinates for structures reported in this article have been deposited at the Cambridge Crystallographic Data Centre (CCDC), under deposition number CCDC 1525201. These data can be obtained free of charge from The Cambridge Crystallographic Data Centre via www.ccdc.cam.ac.uk/data_request/cif. All other data are available from the corresponding authors upon reasonable request.

Received: 8 June 2018 Accepted: 7 September 2018

Published online: 02 October 2018

\section{References}

1. Global Tuberculosis Report 2017. ISBN 978-92-4-156551-6 (World Health Organization, Geneva, 2017).

2. Cohen, T. et al. On the spread and control of MDR-TB epidemics: an examination of trends in anti-tuberculosis drug resistance surveillance data. Drug Resist. Updat. 17, 105-123 (2014).

3. Mishra, R., Shukla, P., Huang, W. \& Hu, N. Gene mutations in mycobacterium tuberculosis: multidrug-resistant $\mathrm{TB}$ as an emerging global public health crisis. Tuberculosis 95, 1-5 (2015).

4. Noor, R. et al. Frequency of extensively drug-resistant tuberculosis (XDR-TB) among re-treatment cases in NIDCH, Dhaka, Bangladesh. J. Infect. Chemother. 19, 243-248 (2013).

5. Parida, S. K. et al. Totally drug-resistant tuberculosis and adjunct therapies. J. Intern. Med. 277, 388-405 (2015).

6. Francis, J. K. \& Higgins, E. Permanent peripheral neuropathy: a case report on a rare but serious debilitating side-effect of fluoroquinolone administration. $J$. Invest. Med. High Impact Case Rep. 2, 1-4 (2014).

7. FDA Safety Announcement 2013: https://www.fda.gov/downloads/drugs/ drugsafety/ucm365078.pdf-The FDA requires label changes to warn of risk for possibly permanent nerve damage from antibacterial fluoroquinolone drugs taken by mouth or by injection (Accessed 13 December 2017).

8. Warner, D. F. \& Mizrahi, V. Shortening treatment for tuberculosis-back to basics. N. Engl. J. Med. 371, 1642-1643 (2014).

9. Horsburgh, C. R., Barry, C. E. \& Lange, C. Treatment of tuberculosis. N. Engl J. Med. 373, 2149-2160 (2015).

10. World Malaria Report 2017. ISBN: 9789241565523 (World Health Organization, Geneva, 2017).

11. Ashley, E. A. et al. Spread of artemisinin resistance in plasmodium falciparum malaria. N. Engl. J. Med. 371, 411-423 (2014).

12. Mbengue, A. et al. A molecular mechanism of artemisinin resistance in plasmodium falciparum malaria. Nature 520, 683-687 (2015).

13. Alday, P. H. \& Doggett, J. S. Drugs in development for toxoplasmosis advances, challenges, and current status. Drug Des. Dev. Ther. 11, 273-293 (2017).

14. Neville, A. J. et al. Clinically available medicines demonstrating antitoxoplasma activity. Antimicrob. Agents Chemother. 59, 7161-7169 (2015).

15. Dubey, J. P., Hemphill, A., Calero-Bernal, R. \& Schares, G. Neosporosis in Animals (CRC Press/Taylor \& Francis: Boca Raton, FL, USA, 2017).

16. Haynes, R. K. South African National Medical Research Council Flagship Project "Development to the clinical phase of oxidant and redox drug combinations for treatment of malaria, TB and related diseases". http://www. mrc.ac.za/strategic/flagship.htm (Accessed 2 December 2017).

17. Coertzen, D. et al. Artemisone and artemiside-potent pan-reactive antimalarial agents that also synergize redox imbalance in P. falciparum transmissible gametocyte stages. Antimicrob. Agents Chemother. 62, e02214-17 (2018) 
18. Wondrak, G. T. Redox-directed cancer therapeutics: molecular mechanisms and opportunities. Antioxid. Redox Signal. 11, 3013-3069 (2009).

19. Andriole, V. T. The quinolones-past, present and future. Clin. Infect. Dis. 41, S113 (2005).

20. Ginsburg, A. S., Grosset, J. H. \& Bishai, W. R. Fluoroquinolones, tuberculosis, and resistance. Lancet Infect. Dis. 3, 432-442 (2003).

21. Ryley, J. F. \& Peters, W. The antimalarial activity of some quinolone esters Ann. Trop. Med. Parasitol. 64, 209-222 (1970).

22. Cross, R. M. et al. Orally bioavailable 6-chloro-7-methoxy-4(1H)-quinolones efficacious against multiple stages of plasmodium. J. Med. Chem. 57, 8860-8879 (2014).

23. Miley, G. P. et al. ELQ-300 prodrugs for enhanced delivery and single-dose cure of malaria. Antimicrob. Agents Chemother. 59, 5555-5560 (2015).

24. Stickles, A. M. et al. Atovaquone and ELQ-300 combination therapy: a novel dual-site cytochrome bc1 inhibition strategy for malaria. Antimicrob. Agents Chemother. 60, 4853-4859 (2016).

25. Monastyrskyi, A., Kyle, D. E. \& Manetsch, R. 4(1H)-Pyridone and 4(1H)quinolone derivatives as antimalarials with erythrocytic, exoerythrocytic, and transmission blocking activities. Curr. Top. Med. Chem. 14, 1693-1705 (2014).

26. Anquetin, G. et al. Quinolone-based drugs against toxoplasma gondii and plasmodium spp. Curr. Drug Targets Infect. Disord. 5, 227-2245 (2005).

27. Doggett, J. S. et al. Endochin-like quinolones are highly efficacious against acute and latent experimental toxoplasmosis. Proc. Natl Acad. Sci. USA 109, 15936-15941 (2012).

28. Taylor, M. A. \& Bartram, D. J. The history of decoquinate in the control of coccidial infections in ruminants. J. Vet. Pharmacol. Ther. 35, 417-427 (2012).

29. Public release summary of the new active decoquinate in the product deccox. Australian Pesticides \& Veterinary Medicines Authority, ISBN: 978-1-92539020-9 (2016).

30. Nam, T.-G. et al. A chemical genomic analysis of decoquinate, a plasmodium falciparum cytochrome b inhibitor. Acs Chem. Biol. 6, 1214-1222 (2011).

31. Da Cruz, F. P. et al. Drug screen targeted at plasmodium liver stages identifies a potent multistage antimalarial drug. J. Infect. Dis. 205, 1278-1286 (2012).

32. Ricketts, A. P. et al. Toxoplasma gondii: susceptibility and development of resistance to anticoccidial drugs in vitro. Antimicrob. Agents Chemother. 37, 2358-2363 (1993).

33. Lenaerts, A. et al. Heterogeneity in tuberculosis pathology, microenvironments and therapeutic responses. Immunol. Rev. 264, 1-20 (2015).

34. Via, L. E. et al. A sterilizing tuberculosis treatment regimen is associated with faster clearance of bacteria in cavitary lesions in marmosets. Antimicrob. Agents Chemother. 59, 4181-4189 (2015).

35. Sarathy, J. P. et al. Prediction of drug penetration in tuberculosis lesions. ACS Infect. Dis. 2, 552-563 (2016).

36. Lemke, T. L. Review of organic functional groups: introduction to medicinal organic chemistry. In Functional Derivatives of Carboxylic Acids, (ed Meredith Brittain) Ch. 12, 59-62 (Lippincott, W. \& Wilkins, Baltimore, MD, 2003).

37. Uetrecht, J. P. \& Trager, W. Drug Metabolism: Chemical and Enzymatic Aspects. Ch. 6, 120 (CRC Press, Boca Raton, FL, 2007).

38. Beteck, R. M. et al. Straightforward conversion of decoquinate into inexpensive tractable new derivatives with significant antimalarial activities. Bioorg. Med. Chem. Lett. 26, 3006-3009 (2016).

39. Igarashi, Y. et al. Synthesis and evaluation of carbamate prodrugs of a phenolic compound. Chem. Pharm. Bull. 55, 328-333 (2007).

40. Zhou, M. et al. Synthesis and biological evaluation of novel 10-substituted-7-ethyl10-hydroxycamptothecin (SN-38) prodrugs. Molecules 19, 19718-19731 (2014).

41. Breugst, M. \& Mayr, H. Ambident reactivities of pyridone anions. J. Am. Chem. Soc. 132, 15380-15389 (2010).

42. Mayr, H., Breugst, M. \& Ofial, A. R. Farewell to the HSAB treatment of ambident reactivity. Angew. Chem. Int. Ed. 50, 6470-6505 (2011).

43. Katritzky, A. R. Handbook of Heterocyclic Chemistry 185-186, 225 (Pergamon Press, Oxford, 1985).

44. Furuta, T. et al. Identification of potent and selective inhibitors of PDGF receptor autophosphorylation. J. Med. Chem. 49, 2186-2192 (2006).

45. Zewge, D. et al. A mild and efficient synthesis of 4-quinolones and quinolone heterocycles. J. Org. Chem. 72, 4276-4279 (2007).

46. Mistry, N. et al. Synthesis and pharmacological profiling of analogues of benzyl quinolone carboxylic acid (BQCA) as allosteric modulators of the M1 muscarinic receptor. J. Med. Chem. 56, 5151-5172 (2013).

47. La Plante, S. R. et al. N- versus O-alkylation: Utilizing NMR methods to establish reliable primary structure determinations for drug discovery. Bioorg. Med. Chem. Lett. 23, 4663-4668 (2013).

48. Pinto, D. C., Santos, C. M. \& Silva, A. M. Advanced NMR techniques for structural characterization of heterocyclic structures. In Recent Research Developments in Heterocyclic Chemistry (ed. Pinho e Melo, T. M. V. D.) ISBN 81-308-0169-8.

49. SDBSWeb; National Institute of Advanced Industrial Science and Technology. https://sdbs.db.aist.go.jp (Accessed 17 December 2017).
50. Dolomanov, O. V. et al. A complete structure solution, refinement and analysis program. J. Appl. Cryst. 42, 339-341 (2009).

51. Bourhis, L. J. et al. The anatomy of a comprehensive constrained, restrained refinement program for the modern computing environment-Olex2 dissected. Acta Cryst. A71, 59-75 (2015).

52. Stringer, T. R. et al. Antimicrobial activity of organometallic isonicotinyl and pyrazinyl ferrocenyl-derived complexes. Dalton Trans. 46, 9875-9885 (2017).

53. Arora, K. B. et al. Respiratory flexibility in response to inhibition of cytochrome c oxidase in mycobacterium tuberculosis. Antimicrob. Agents Chemother. 58, 6962-6965 (2014).

54. van der Westhuyzen, R. S. et al. Pyrrolo[3,4-c]pyridine-1,3(2H)-diones: a novel antimycobacterial class targeting mycobacterial respiration. J. Med. Chem. 58, 9371-9381 (2015).

55. Moosa, A. et al. Susceptibility of mycobacterium tuberculosis cytochrome bd oxidase mutants to compounds targeting the terminal respiratory oxidase, cytochrome c. Antimicrob. Agents Chemother. 61, e01338-17 (2017).

56. Lamprecht, D. A. et al. Turning the respiratory flexibility of mycobacterium tuberculosis against itself. Nat. Commun. 7, 123932 (2016).

57. Naran, K. A. et al. Bioluminescent reporters for rapid mechanism of action assessment in tuberculosis drug discovery. Antimicrob. Agents Chemother. 60 , 6748-6757 (2016).

58. Singh, V. et al. The complex mechanism of antimycobacterial action of 5fluorouracil. Chem. Biol. 22, 63-75 (2015).

59. Verlinden, B. K. et al. Discovery of novel alkylated (bis)urea and (bis)thiourea polyamine analogues with potent antimalarial activities. J. Med. Chem. 54, 6624-6633 (2011).

60. Trager, W. \& Jensen, J. B. Human malaria parasites in continuous culture. Science 20, 673-675 (1976).

61. Neelarapu, R. et al. Design and synthesis of orally bioavailable piperazine substituted $4(1 \mathrm{H})$-quinolones with potent antimalarial activity: structureactivity and structure-property relationship studies. J. Med. Chem. 61, 1450-1473 (2018).

62. Reader, J. et al. Nowhere to hide: interrogating different metabolic parameters of Plasmodium falciparum gametocytes in a transmission blocking drug discovery pipeline towards malaria elimination. Malar. J. 14, 213 (2015).

63. Swann, J. et al. High-throughput luciferase-based assay for the discovery of therapeutics that prevent malaria. ACS Infect. Dis. 2, 281-293 (2016).

64. Stephens, M. A. et al. The adaptive potential of a survival artist: characterization of the in vitro interactions of toxoplasma gondii tachyzoites with di-cationic compounds in human fibroblast cell cultures. Parasitology 139, 208-220 (2012).

65. Ojo, K. K. et al. Neospora caninum calcium-dependent protein kinase 1 is an effective drug target for neosporosis therapy. PLoS ONE 9, e92929 (2014).

66. Piton, J. C. et al. Structural studies of mycobacterium tuberculosis DprE1 interacting with its inhibitors. Drug Discov. Today 22, 526-533 (2016).

67. Li, W. A. et al. Novel insights into the mechanism of inhibition of MmpL3, a target of multiple pharmacophores in mycobacterium tuberculosis. Antimicrob. Agents Chemother. 58, 6413-6423 (2014).

68. Goldman, R. C. Why are membrane targets discovered by phenotypic screens and genome sequencing in mycobacterium tuberculosis? Tuberculosis $\mathbf{9 3}$, 569-588 (2013).

\section{Acknowledgements}

This project is funded by the South African Medical Research Council (SAMRC) with funds from National Treasury under its Economic Competitiveness and Support Package for the North-West University (NWU) Flagship Project MAL-TB Redox. The SAMRC through the Strategic Health Innovation Partnerships provided support to D.F.W., and the South African National Research Foundation provided support to L.-M.B. (UID 84627) and R.K.H. (UIDs 90682 and 98934). A.H. is supported by the Swiss National Science Foundation (Grant 310030_165782), E.A.W. by the NIH (Grants 5R01AI090141 and R01AI103058), the Bill \& Melinda Gates Foundation (OPP1086217, OPP1141300), and the Medicines for Malaria Venture. G.Z. (Grants 16103714 and 16104315), I.D.W. and R.V.de.G. (Grant 16306515) are supported by the Research Grants Council of Hong Kong, and R.V.de.G. by a studentship from HKUST. R.M.B., D.D.N.D., F.J.S., and R.K.H. received financial support from NWU. Dr. Herman H-Y. Sung (HKUST) is thanked for assistance with the X-ray diffraction studies. Mr. A. Joubert and Dr. J.H.L. Jordaan are thanked for recording the NMR and MS spectra, respectively, at NWU. Dr. Sergio Wittlin, Group Leader, Parasite Chemotherapy, Swiss Tropical and Public Health Institute, Basel, Switzerland, is thanked for conducting the screens of compound 22 against drug-sensitive and atovaquone-resistant $P f$, and Natasha Kolesnikova, CSIR Biosciences Pharmacology Group, CSIR Biosciences, Pretoria, South Africa for conducting the in vitro cytotoxicity assays against the WI-38 cell line. Any opinion, finding and conclusion or recommendation expressed in this material is that of the authors and the SA NRF does not accept any liability in this regard. 


\section{Author contributions}

R.K.H. proposed use of the DQ template. All authors contributed to writing the manuscript. R.M.B., D.D.N.D., and R.K.H. designed the derivatives, and R.M.B. conducted the synthetic chemistry; R.M.B. designed and synthesized the chain-shortened analogues. G.Z. and F.R. conducted the high-field NMR experiments. R.V.de.G., I.D.W. conducted the X-ray crystallographic determinations, R.S., D.F.W. conducted the Mtb assays with HS37Rv and cydKO mutants, and the PiniB-LUX and PrecA-LUX reporter assays, J.S.M., D.A.L., A.J.C.S. conducted the OCR assays, L.-M.B., D.C., M.E.v.d.W. and J.R. conducted assays with $P f$, M.A., K.E., and E.A.W. conducted $P b$ liver stage and HepG2 cytotoxicity assays, and A.H. and J.M. conducted assays with $\mathrm{Tg}$ and $\mathrm{Nc}$.

\section{Additional information}

Supplementary information accompanies this paper at https://doi.org/10.1038/s42004018-0062-7.

Competing interests: The authors declare no competing interests.

Reprints and permission information is available online at http://npg.nature.com/ reprintsandpermissions/
Publisher's note: Springer Nature remains neutral with regard to jurisdictional claims in published maps and institutional affiliations.

\section{(c) (i)}

Open Access This article is licensed under a Creative Commons Attribution 4.0 International License, which permits use, sharing, adaptation, distribution and reproduction in any medium or format, as long as you give appropriate credit to the original author(s) and the source, provide a link to the Creative Commons license, and indicate if changes were made. The images or other third party material in this article are included in the article's Creative Commons license, unless indicated otherwise in a credit line to the material. If material is not included in the article's Creative Commons license and your intended use is not permitted by statutory regulation or exceeds the permitted use, you will need to obtain permission directly from the copyright holder. To view a copy of this license, visit http://creativecommons.org/ licenses/by/4.0/.

(C) The Author(s) 2018 